\title{
METHOD OF IDENTIFYING AN OPERATING REGIME IN A BUBBLING FLUIDIZED BED GASIFICATION REACTOR
}

\author{
RAJAN JAISWAL, NORA C. I. S. FURUVIK, RAJAN K. THAPA \& BRITT M. E. MOLDESTAD \\ Department of Natural Science and Maritime Science, University of South-Eastern Norway, Porsgrunn, Norway
}

\begin{abstract}
This work presents a new method for identifying the bubbling regime of a fluidized bed gasification reactor. The method has been developed using experimental measurements and a computational model. Pressure drops are measured in experiments, and pressure drop as well as solid volume fraction fluctuations are calculated by implementing the model. Experiments are carried out with sand and limestone particles of mean diameter $346 \mu \mathrm{m}$ and $672 \mu \mathrm{m}$, respectively. A computational particle fluid dynamics (CPFD) model has been developed for the reactor and implemented using a commercial CPFD software Barracuda VR. The model is validated against experimental measurements. The validated model is used to analyse the fluctuation of pressure drop and solid volume fraction as a function of superficial air velocity. The change in standard deviation of pressure drop and solid volume fraction fluctuation is used to predict the transition from one regime to another. The method can be used in the design and operation of a bubbling fluidized bed gasification reactor. The results show that the minimum fluidization velocity for sand and limestone are $0.135 \mathrm{~m} / \mathrm{s}$ and $0.36 \mathrm{~m} / \mathrm{s}$, respectively and are independent of the particle aspect ratio. Both types of particle beds make the transition into bubbling regime as soon as they get fluidized. The bed aspect ratios have almost no effect on the onset of bubbling fluidization regime. The slugging velocity decreases with increasing aspect ratio for both types of particles. The operating range of the bubbling fluidized bed for sand particle is $0.2-0.4 \mathrm{~m} / \mathrm{s}$ and $0.5-0.8 \mathrm{~m} / \mathrm{s}$ for the limestone particles.

Keywords: biomass gasification, CPFD, fluidized bed, pressure drop, solid volume fraction.
\end{abstract}

\section{INTRODUCTION}

One of the major challenges the world is facing is to fulfil the high energy demand and address the pollution from the energy conversion technologies. Biomass gasification is a green energy technology that thermochemically converts forestry and agricultural residues into a mixture of high calorific value gases such as hydrogen, methane, and carbon monoxide. This technology not only helps to cope with environmental problems but also contributes to energy supply at a large scale [1], [2]. Availability of sufficient biomass feedstock in the form of wastes from forest, agriculture and industries makes the gasification process a promising technology.

There are many types of gasification reactors. Bubbling fluidized bed (BFB) is one of them [3]. The main advantages of a BFB gasification reactor are that it ensures uniform heat distribution and proper mixing of solid and gas [4]. The overall efficiency of the conversion process is depended on the number and size of bubbles that grow and rise in the bed. The bubbles are responsible for gas solid mixing and heat transfer. The smaller bubbles cannot contribute much to the uniform mixing and heat transfer while, too large bubbles may bypass the bed making the process less efficient. The size of the bubbles in the bubbling regime is a function of the fluidizing gas velocity. Thus, identifying the optimum range of fluidizing gas velocity in the gasification process is important. This optimum range is fixed for the given particles with similar physical properties such as size, size distribution, sphericity and density. Identifying and operating the reactor in this velocity range, known as fluidization regime, gives optimum yield from the gasification process.

Moreover, one of the major challenges in the biomass gasification is to maintain air fuel ratio to obtained maximum gas yield without loss of energy. Excess supply of fluidizing air 
may add more oxygen to the process. This could shift the conversion process into combustion rather than gasification. Additional heat has to be supplied to heat up the excess air, which leads to loss of energy from the system. Therefore, it is important to find out the optimum gas velocity, which maintains the fluidizing regime ensuring good mixing and heat transfer and at the same time, preventing the use of excess gas and loss of energy in the process.

This study investigates fluidization regimes from minimum fluidization to bubbling and transition from bubbling to slugging regime using experimental and computational methods. The transitions from minimum fluidization to bubbling and from bubbling to slugging regimes are predicted using pressure drop and solid volume fraction fluctuations. The changes in standard deviation of pressure drop at different gas velocities are marked as the transition velocities between the different regimes. The transitions of the regimes with the change in gas velocities are analysed with the solid volume fraction fluctuation (see section 4). These transition velocities are useful to determine the bubbling fluidized regime for given particles and the velocity range to operate the bubbling fluidized bed gasification reactor.

Experiments are carried out with sand and limestone particles with five sets of aspect ratios $(H / D): 0.7,1,1.5,2,2.5$ in a cold bed rig, where $H$ is the static bed height and $D$ is the diameter of the bed. The reason for choosing sand and limestone particles is that sand particles are commonly used as bed materials in bubbling fluidized bed gasification reactors and limestone can be potential particles as they can be used for $\mathrm{CO}_{2}$ capture from the gasification process. A cold model of the gasification reactor is used in experimental measurements. Using the cold model, the fluid dynamic properties of the gas-solid flow can be measured without using heat. The cold model (experimental rig) is located at the University of South-Eastern Norway.

A computational particle fluid dynamic (CPFD) model for the experimental reactor has been developed and implemented using the commercial software Barracuda VR. Barracuda uses the Multi-Phase Particle in Cell (MP-PIC) approach where, particles with similar properties such as diameters and densities are grouped together to form the computational unit of computational particles termed as parcels. A blended approach of both Eulerian and Lagrangian is used for the modelling of gas-solid interaction. The main advantage of using the MP-PIC method over the other computational methods is that it saves computational time and cost [5]-[8]. The CPFD model is used to simulate the flow behaviour of the bed material at different gas velocities and aspect ratios. The model can predict the operating regime of the bubbling fluidized bed thus, can be useful in the design and operation of the gasification reactor.

\section{EXPERIMENTS}

Experiments were carried out in the cold model of the bubbling fluidized bed gasification reactor shown in Fig. 1. The cold model is a three-dimensional transparent column with a diameter of $8.4 \mathrm{~cm}$ and height of $140 \mathrm{~cm}$. An air distributor present at the bottom of the column ensures the uniform air supply. Nine sets of pressure transducers are installed along the wall of the column. The changes in pressures due to changes in superficial gas velocities are measured via the pressure transducers and are recorded using a LabView program. The data are further imported in a MATLAB program for analysis. The pressure drop due to the total weight of the bed at each flow rate is calculated by subtracting the air distributor pressure from the pressure measured by the pressure transducer P1. An expression for the total pressure drop due to the weight of the bed is given by:

$$
p_{T}=p_{1}-\Delta p_{d} \text {. }
$$



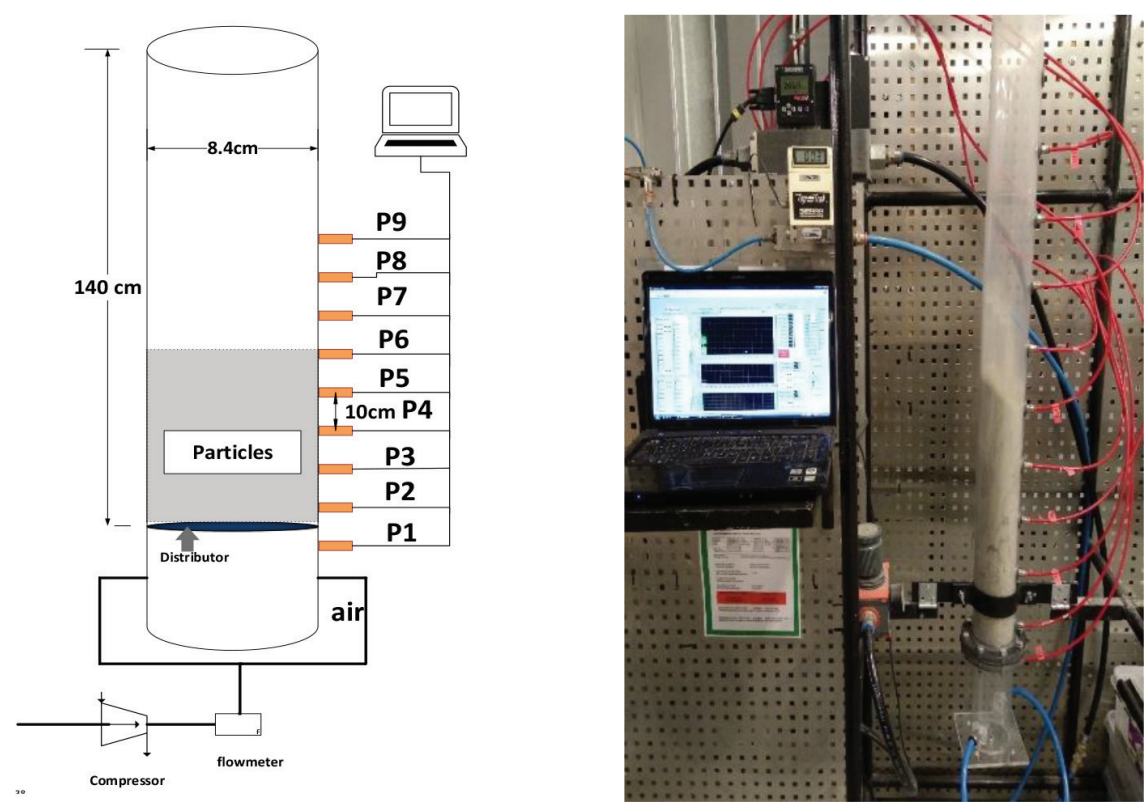

Figure 1: Schematic diagram of the experimental setup.

where $p_{T}$ is the total gauge pressure due to the weight of the bed, $p_{1}$ is the gauge pressure at P1 (see Fig. 1) and $\Delta p_{d}$ is the pressure drop over the air distributor.

The particles are fed into the column from the top. The superficial air velocity is increased gradually, regulated by a control valve and the pressure readings are recorded. For each flowrate, data are logged for more than one minute with the sampling time of one second. A minimum of $60 \mathrm{~s}$ is used to establish the flow, prior to logging the data. The particles are removed from the column after each experimental series and the column is refilled with new particles since the particles exhibit different properties once they are fluidized.

The particle properties used for the experiments are listed in Table 1. The mean diameter is calculated from:

$$
d_{m}=\frac{1}{\sum\left(\frac{w_{s}}{d_{s}}\right)_{i}} .
$$

where $d_{m}$ is the mean diameter, $w_{s}$ the weight fraction and $d_{s}$ is the diameter of the particles in the sieve range.

Table 1: Particle properties.

\begin{tabular}{lccc}
\hline Particles & $\begin{array}{c}\text { Mean diameter } \\
(\boldsymbol{\mu m})\end{array}$ & $\begin{array}{c}\text { Density } \\
\mathbf{k g} / \mathbf{m}^{\mathbf{3}}\end{array}$ & $\begin{array}{c}\text { Solid volume } \\
\text { fraction }\end{array}$ \\
\hline Sand & 346 & 2650 & 0.52 \\
Limestone & 672 & 2837 & 0.47 \\
\hline
\end{tabular}




\section{COMPUTATIONAL MODEL}

A cylindrical geometry, similar to that of the experimental rig, that is, with a $140 \mathrm{~cm}$ height and $8.4 \mathrm{~cm}$ diameter, is modelled using Computer Aided Design (CAD) software and imported in Barracuda VR. A uniform grid of a total 12000 cells is generated to the geometry, as shown in Fig. 2c. The base material, particle species and the boundary conditions are specified similar to those of the experimental set up. The bottom of the column is set as inlet flow boundary (Fig. 2b, marked with red colour) while the top of the column as the pressure boundary (Fig. 2b, yellow colour). The monitoring points are set at the centre of the column at the same heights as in the experimental setup as shown in Fig. 2a.

The particle size distribution and close pack volume fraction used for the simulations are the same as in the experiments (see Table 1). The maximum momentum from the redirection of particle collisions is assumed to be $40 \%$ with normal-to-wall and tangential-to-wall momentum retention being 0.3 and 0.99 , respectively. The operating conditions used in the simulations are summarized in Table 2.

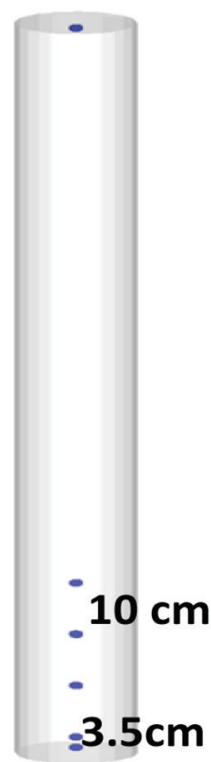

(a)

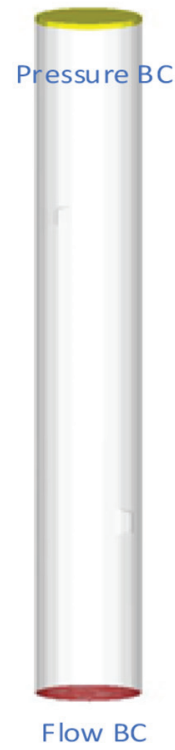

(b)

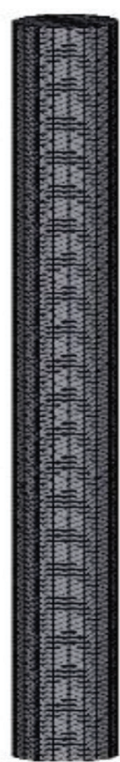

(c)

Figure 2: (a) Transient data points, (b) Pressure boundaries and (c) Grid.

Table 2: Operating conditions.

\section{Fluidizing gas}

Fluid temperature

Superficial gas velocity

Static bed heights

Outlet pressure

Simulation time for each flowrate
Air

Ambient (300 K)

0.016 to $2 \mathrm{~m} / \mathrm{s}$

$(0.7,1,1.5,2,2.5) \mathrm{D}$

$101325 \mathrm{~Pa}$

$20 \mathrm{~s}$ 
Barracuda VR uses the Multi-Phase Particle in Cell (MP-PIC) approach, where combined Eulerian and Lagrangian methods are used for the modelling of gas-solid interaction. The fluid phase is solved as the continuum, while the particle phase is solved using the Lagrangian method. The equations involved in the computational model have been proposed by Andrews and O'Rourke [9], Snider [10].

\section{RESULTS AND DISCUSSION}

\subsection{Model validation}

Experiments are carried out with the sand and limestone particles both with five sets of aspect ratios: $0.7,1,1.5,2,2.5$. Experimental results for the limestone particle of size $346 \mu \mathrm{m}$ at the aspect ratio of 2 are shown as the blue curve in Fig. 3. The figure shows pressure drop at various superficial air velocities. The pressure drop increases, reaches a peak value and remains constant with the increase in superficial gas velocity. Figure 3 also shows the results from simulation using the CPFD model. The results presented by the red curve show similar fluid dynamic behaviour of the bed. The maximum deviation between the experimental and simulation results is approximately $10 \%$. With these results, the model is assumed to give approximately similar results to those from experiments and is used for further investigation of the flow regimes of the fluidized bed reactor.

\subsection{Minimum fluidization}

Figure 4 shows the pressure drop versus superficial gas velocity for limestone particles of size $672 \mu \mathrm{m}$ for various aspect ratios. With increase in gas velocity, the pressure drop increases, reaches a peak value and remains constant. The gas velocity at the maximum pressure drop is the minimum fluidization velocity. At this stage, the total weight of the bed is counterbalanced by the drag force of the gas, thus, the bed remains suspended. The minimum fluidization velocity for limestone is $0.36 \mathrm{~m} / \mathrm{s}$. The figure also shows the change in pressure drop for the aspect ratios $0.7,1,1.5,2$ and 2.5 . With the increase in aspect ratio, the pressure drop increases while the minimum fluidization velocity remains constant.

Figure 5 shows the pressure gradient at different aspect ratios with change in gas velocity. The pressure gradient and minimum fluidization velocity do not change with the change in aspect ratio.

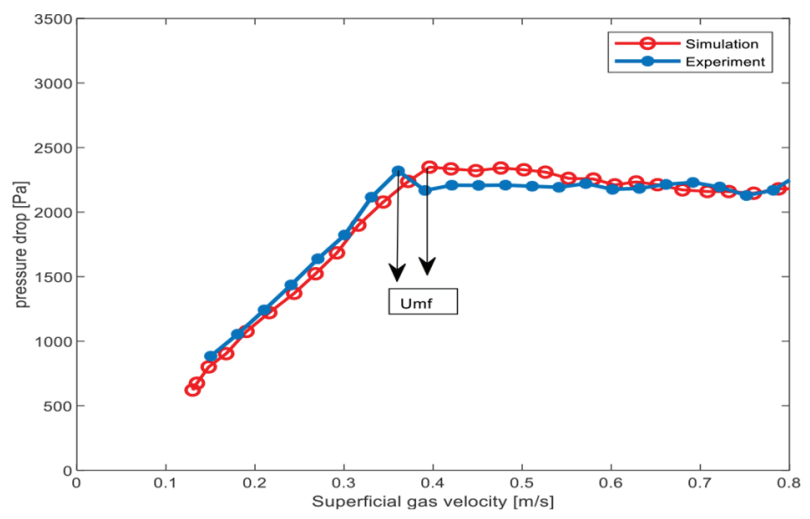

Figure 3: Pressure drop vs superficial gas velocity. 


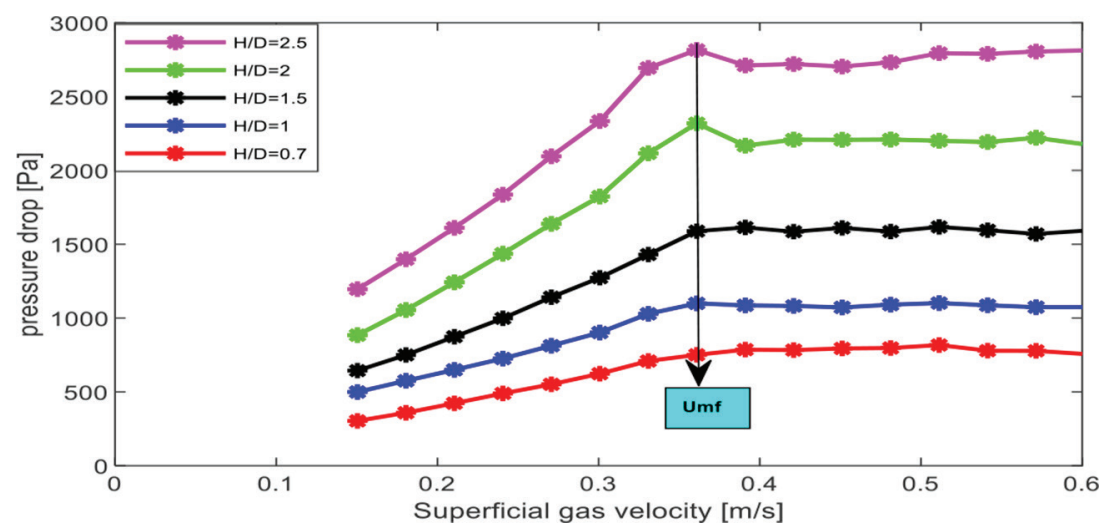

Figure 4: Pressure drop over the total bed vs superficial gas velocities for limestone.

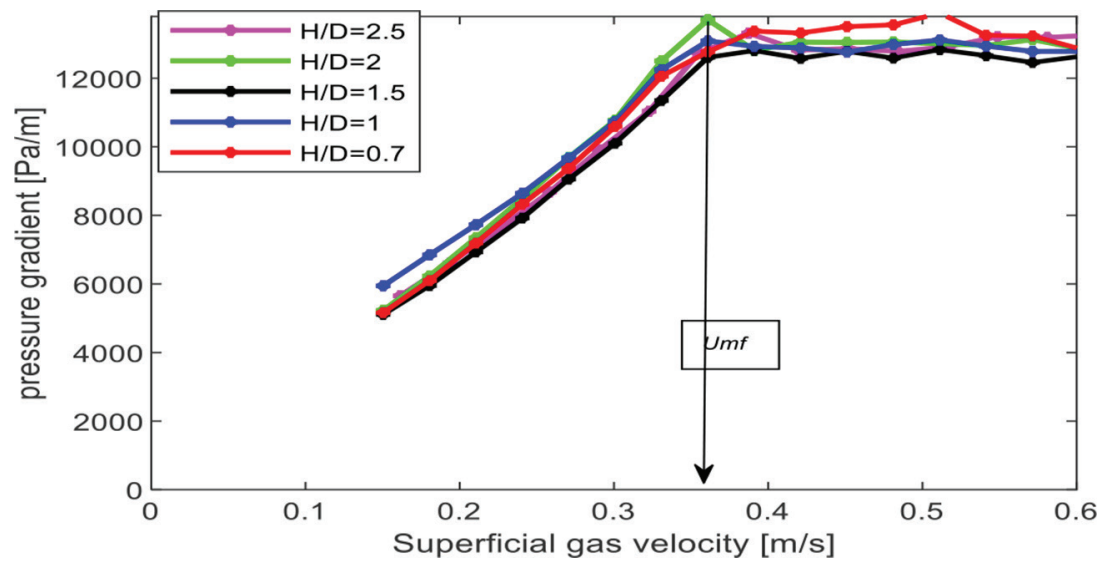

Figure 5: Pressure drop due to height of the bed vs superficial gas velocities for limestone.

Figure 6 shows the experimental pressure drop plotted against superficial gas velocity for sand particles. The result shows that the minimum fluidization velocity for sand particles is $0.135 \mathrm{~m} / \mathrm{s}$ and it remained constant with increase in aspect ratio.

\subsection{Identifying the operating regimes}

The fluctuation of pressure drops and solid volume fractions as a function of the superficial gas velocities are used to analyse the transition from one fluidization regime to another. The standard deviations of pressure fluctuation in the bed are plotted against the superficial gas velocities for the sand particles at the aspect ratio of 0.7 as shown in Fig. 7. Initially, the fluctuation of standard deviation remains zero, which explains the non-fluidized state of the bed. At the minimum bubbling velocity, significant fluctuations are observed. With further increase in gas velocity, small bubbles appear in the bed. The appearance of the first bubble inside the bed is marked as the onset of bubbling fluidization regime and the corresponding gas velocity is minimum bubbling velocity $\left(\mathrm{U}_{\mathrm{mb}}\right.$ ). With the increase in gas velocity, the number and size of bubbles grow and rise in the bed. Formation and collapse of the bubbles in the bed cause 


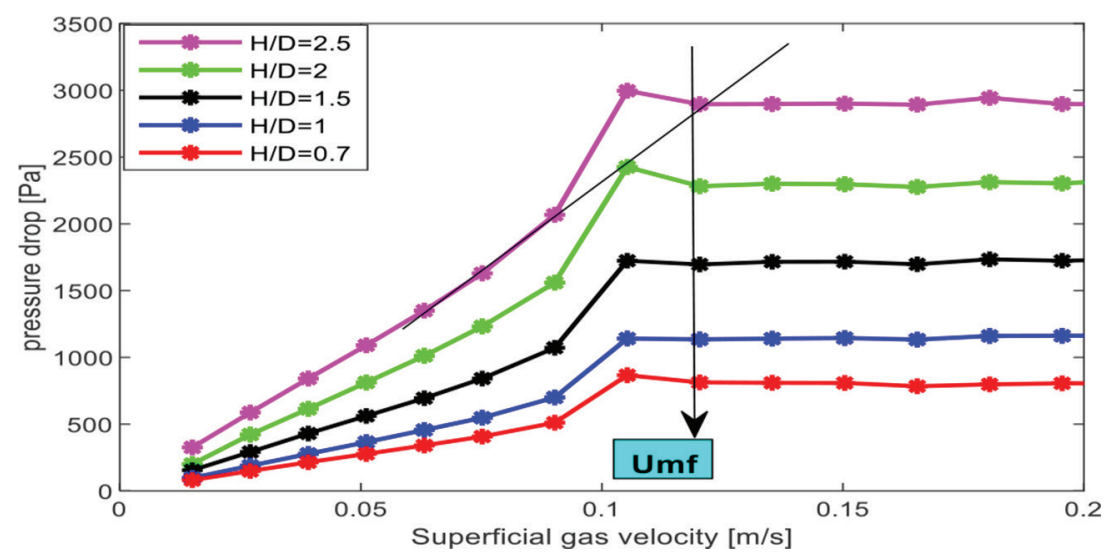

Figure 6: Pressure drop over the total bed vs superficial gas velocity of the sand particle.

the pressure fluctuation. This variation is seen in Fig. 7. Above a gas velocity of $0.2 \mathrm{~m} / \mathrm{s}$, the fluctuation in the standard deviation of pressure drop increases significantly. When the bubble size increases to $0.3-0.6$ times the diameter of the reactor, the bed transits to the slugging regime [12]. During the onset of the slugging regimes, a few bubbles followed by a slug appear in the bed and the velocity of gas at this point is called as minimum slugging velocity $\left(\mathrm{U}_{\mathrm{ms}}\right)$. With the increase in gas velocity above $0.4 \mathrm{~m} / \mathrm{s}$, the pressure fluctuation increases rapidly and the particles in bed start vigorous movement.

The fluctuations of the solid volume fraction corresponding to the onset of each regime are shown in Fig. 8. At the minimum fluidization velocity of $0.145 \mathrm{~m} / \mathrm{s}$, the particle volume fraction fluctuates between 0.52 and 0.5 . At the gas velocity of $0.2 \mathrm{~m} / \mathrm{s}$, the solid volume fraction decreases and fluctuates between 0.5 and 0.45 marked as the onset of the bubbling regime (see Fig. 7). The fluctuation indicates the formation of bubbles in the bed. The fluctuation of solid volume fraction from 0.4 to 0.2 at the air velocity of $0.4 \mathrm{~m} / \mathrm{s}$ indicates the beginning of the slug. The fluctuation gets vigorous at the air velocity of $0.9 \mathrm{~m} / \mathrm{s}$ known as critical velocity [13].

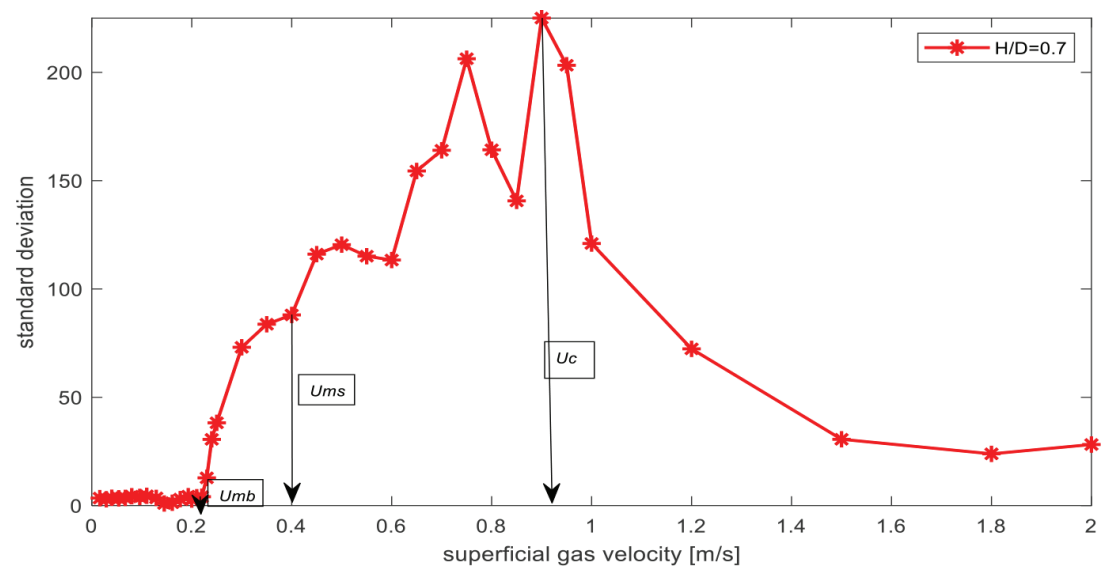

Figure 7: Standard deviation of pressure fluctuation vs superficial gas velocities for sand particles. 

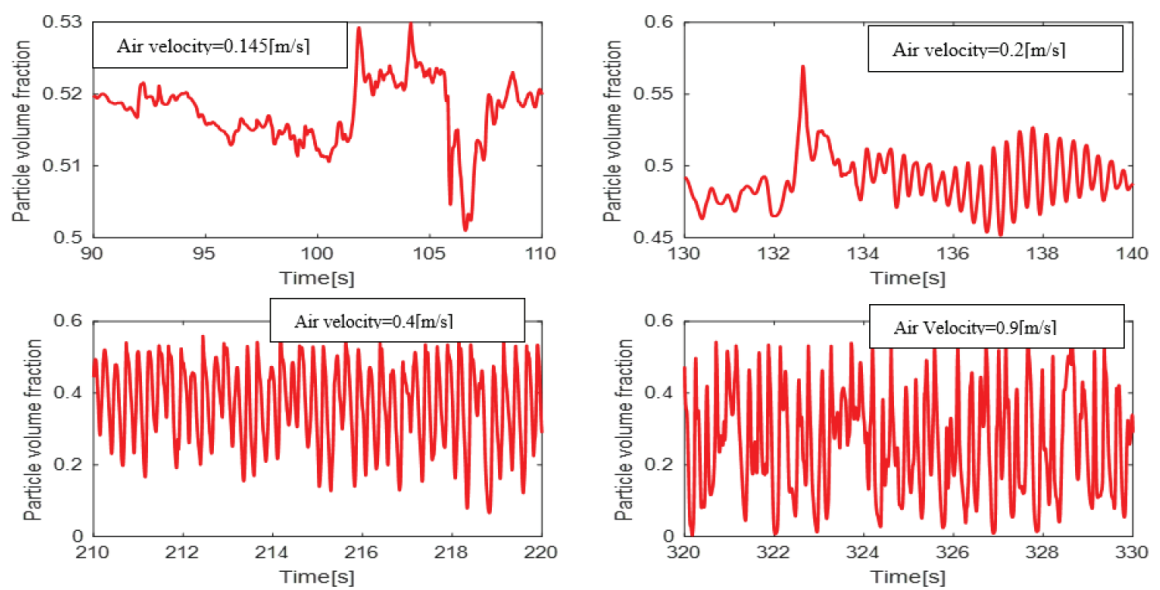

Figure 8: Solid volume fraction fluctuation for the sand and particles.

Figure 9 shows the standard deviation of pressure fluctuations with respect to the change in superficial gas velocities for limestone at the aspect ratio of 2 . The fluctuation begins at minimum bubbling velocity of $0.5 \mathrm{~m} / \mathrm{s}$, and increases further until it reaches the minimum slugging velocity. The operating range for the limestone at the aspect ratio of 2 is identified as $0.5 \frac{\mathrm{m}}{\mathrm{s}}<\mathrm{u}_{0}<0.71 \mathrm{~m} / \mathrm{s}$. The critical velocity for the limestone is identified as $1.1 \mathrm{~m} / \mathrm{s}$.

Figure 10 shows the fluctuation of particle volume fraction during the onset of each regime for limestone. At the air velocity of $0.39 \mathrm{~m} / \mathrm{s}$ there is fluctuation in solid volume fraction 0.47 to 0.45 which is a minimum fluidization condition. Similarly, with the increase in gas velocity to $0.5 \mathrm{~m} / \mathrm{s}$ the first bubble appears in the bed marked as the onset of bubbling regime. The fluctuation is rapid and solid volume fraction changes from 0.45 to 0.35 at the air velocity of $0.71 \mathrm{~m} / \mathrm{s}$. It indicates that the bed starts to slug. With the increase in air velocity to $1.1 \mathrm{~m} / \mathrm{s}$ the fluctuation in solid volume fraction gets vigorous and the particle volume fraction decreases to 0.1 . The superficial gas velocity at this stage is identified as the critical velocity.

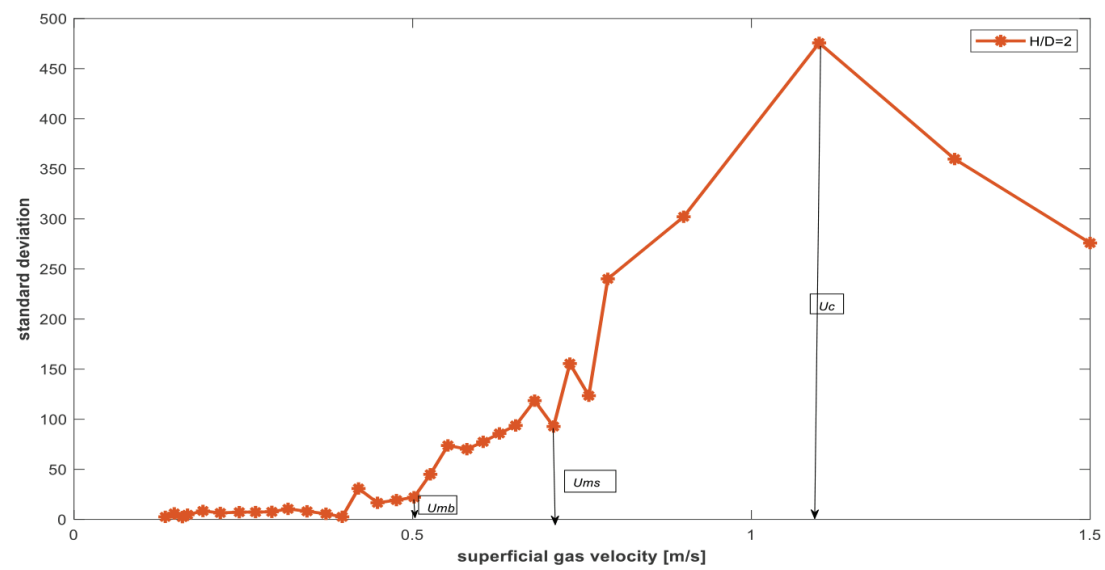

Figure 9: Standard deviation of pressure fluctuation for the limestone as a function of superficial gas velocity. 

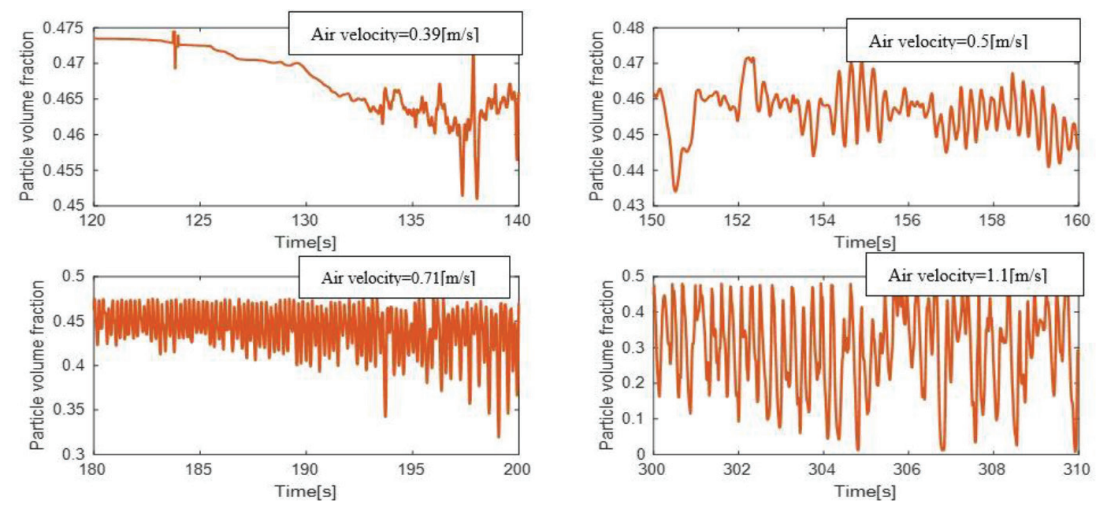

Figure 10: Solid volume fraction fluctuation for the limestone particles.

\subsection{Bubbling fluidization}

Figure 11 shows the onset of bubbling fluidization regime for sand and limestone particles at various aspect ratios. The minimum bubbling velocities of the sand and limestone particles are $0.18 \mathrm{~m} / \mathrm{s}$ and $0.42 \mathrm{~m} / \mathrm{s}$, respectively. For both sand and limestone, the minimum bubbling velocity remains almost constant at all aspect ratios.

\subsection{Slugging}

The onset of minimum slugging velocity for the limestone and sand particles at different aspect ratios is shown in Fig. 12. The onset of minimum slugging velocity for both types of particles decreases with increase in aspect ratio. The slugging velocity of limestone particles decreases from $0.78 \mathrm{~m} / \mathrm{s}$ to $0.64 \mathrm{~m} / \mathrm{s}$ with increase in aspect ratio from 0.7 to 2.5 . For the sand particles, the minimum slugging velocity decreases from $0.4 \mathrm{~m} / \mathrm{s}$ to $0.3 \mathrm{~m} / \mathrm{s}$.

Table 3 shows the range of velocities of bubbling fluidization regime for the sand and limestone particles at different aspect ratio. When the bubbling fluidized bed gasification reactor is operated within the range of velocities given in Table 3, the reactor gives increased efficiency from the gasification process. It is found that the operating range for the sand particles is from $0.2 \mathrm{~m} / \mathrm{s}$ to $0.4 \mathrm{~m} / \mathrm{s}$ depending on the aspect ratio. Similarly, the operating range for limestone is from $0.5 \mathrm{~m} / \mathrm{s}$ to $0.8 \mathrm{~m} / \mathrm{s}$. The operating range for both particles decreases with increase in aspect ratio since the bed slugs with increase in aspect ratio.
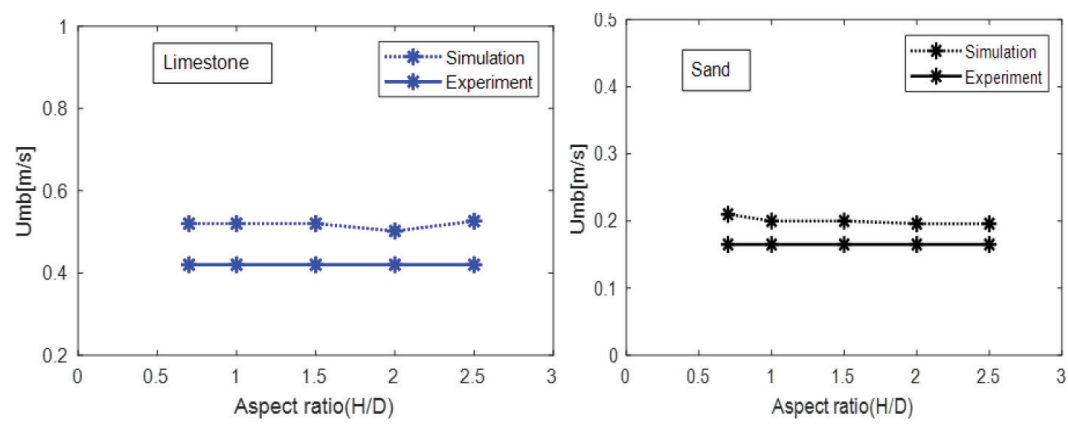

Figure 11: Minimum bubbling velocity for the sand and limestone at different aspect ratio. 

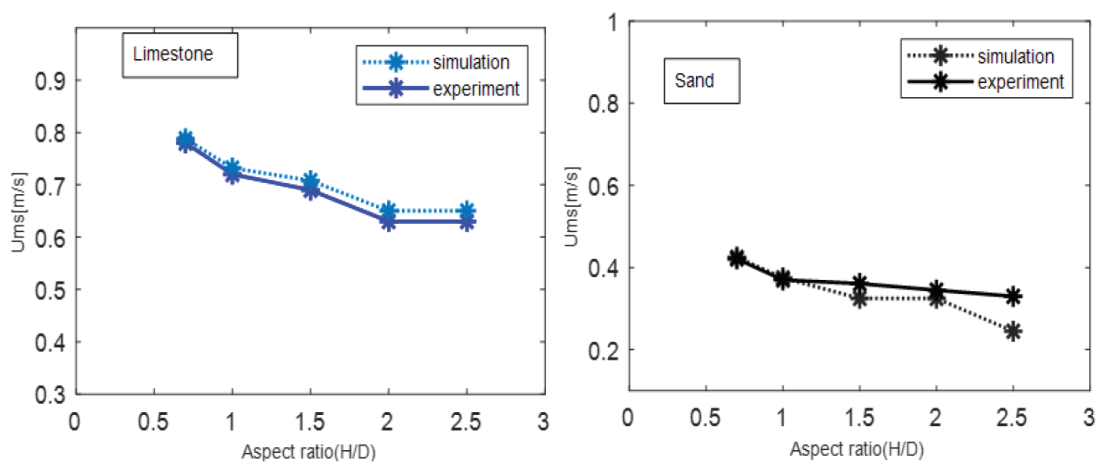

Figure 12: Minimum slugging velocity of limestone and sand particles at different aspect ratios.

Table 3: Operating velocity at different aspect ratio.

\begin{tabular}{ccc}
\hline $\begin{array}{c}\text { Aspect ratio } \\
\text { (H/D) }\end{array}$ & \multicolumn{2}{c}{ Range of bubbling fluidization regime } \\
\hline 0.7 & $0.2-0.4 \mathrm{~m} / \mathrm{s}$ & Limestone \\
1 & $0.2-0.36 \mathrm{~m} / \mathrm{s}$ & $0.5-0.8 \mathrm{~m} / \mathrm{s}$ \\
1.5 & $0.2-0.35 \mathrm{~m} / \mathrm{s}$ & $0.5-0.78 \mathrm{~m} / \mathrm{s}$ \\
2 & $0.2-0.35 \mathrm{~m} / \mathrm{s}$ & $0.5-0.75 \mathrm{~m} / \mathrm{s}$ \\
2.5 & $0.2-0.3 \mathrm{~m} / \mathrm{s}$ & $0.5-0.71 \mathrm{~m} / \mathrm{s}$ \\
\hline
\end{tabular}

\section{CONCLUSION}

The minimum fluidization regime, onset of bubbling regime and transition from bubbling regime to slugging regime are predicted with the analysis of pressure and solid volume fraction fluctuations. The effects of the aspect ratios on the transition of fluidization regimes are identified for sand and limestone particles. A CPFD model is developed and simulated using the CPFD software Barracuda VR. Changes in pressure drop are plotted against the increase in superficial gas velocity. The results show that the minimum fluidization velocity for sand and limestone particles is $0.14 \mathrm{~m} / \mathrm{s}$ and $0.36 \mathrm{~m} / \mathrm{s}$, respectively. The minimum fluidization and bubbling velocities for limestone and sand particles remain constant at various aspect ratios. The slugging velocity decreases with the increase in aspect ratio from 0.7 to 2.5 . The pressure standard deviation indicates that the bubbles start to appear in the bed as soon as the gas velocity exceeds the minimum fluidization state. The operating range for the bubbling fluidized bed is from $0.2 \mathrm{~m} / \mathrm{s}$ to $0.4 \mathrm{~m} / \mathrm{s}$ depending on the aspect ratio, while it varies from $0.5 \mathrm{~m} / \mathrm{s}$ to $0.8 \mathrm{~m} / \mathrm{s}$ for limestone.

\section{REFERENCES}

[1] McKendry, P., Energy production from biomass (part 1): Overview of biomass. Bioresource Technology, 83(1), pp. 37-46, 2002. https://doi.org/10.1016/S09608524(01)00118-3

[2] Demirbas, A., Global renewable energy resources. Energy Sources, 28(8), pp. 779-792, 2006. https://doi.org/10.1080/00908310600718742 
[3] Kern, S., Pfeifer, C. \& Hofbauer, H., Gasification of wood in a dual fluidized bed gasifier: Influence of fuel feeding on process performance. Chemical Engineering Science, 90, pp. 284-298, 2013. https://doi.org/10.1016/j.ces.2012.12.044

[4] Rapagnà, S., Jand N., Kiennemann, A. \& Foscolo, P.U., Steam-gasification of biomass in a fluidised-bed of olivine particles. Biomass and Bioenergy, 19(3), pp. 187-197, 2000. https://doi.org/10.1016/s0961-9534(00)00031-3

[5] Singh, R.I., Brink, A. \& Hupa, M., CFD modeling to study fluidized bed combustion and gasification. Applied Thermal Engineering, 52(2), pp. 585-614, 2013. https://doi. org/10.1016/j.applthermaleng.2012.12.017

[6] Hjertager, B.H., Multi-fluid CFD analysis of chemical reactors. Multiphase reacting flows: modelling and simulation, eds. D.L. Marchisio \& R.O. Fox, Springer, pp. 125-179, 2007.

[7] Xie, J., Zhong, W., Jin, B., Shao, Y. \& Liu, H., Simulation on gasification of forestry residues in fluidized beds by Eulerian-Lagrangian approach. Bioresource Technology, 121, pp. 36-46, 2012. https://doi.org/10.1016/j.biortech.2012.06.080

[8] Thapa, R., Pfeifer, C. \& Halvorsen, B.M., Modeling of reaction kinetics in bubbling fluidized bed biomass gasification reactor. International Journal of Energy and Environment, 5(1), pp. 35-44, 2014.

[9] Andrews, M.J. \& O'Rourke, P.J., The multiphase particle-in-cell (MP-PIC) method for dense particulate flows. International Journal of Multiphase Flow, 22(2), pp. 379-402, 1996. https://doi.org/10.1016/0301-9322(95)00072-0

[10] Snider, D.M., An incompressible three-dimensional multiphase particle-in-cell model for dense particle flows. Journal of Computational Physics, 170(2), pp. 523-549, 2001. https://doi.org/10.1006/jcph.2001.6747

[11] Gidaspow, D., Multiphase Flow and Fluidization: Continuum and Kinetic Theory Descriptions, Academic Press, 1994.

[12] Yates, J., Fundamentals of Fluidized-Bed Chemical Processes, Butterworth-Heinemann, 2013.

[13] Yerushalmi, J. \& Cankurt, N.T., Further studies of the regimes of fluidization. Powder Technology, 24(2), pp. 187-205, 1979. https://doi.org/10.1016/0032-5910(79)87036-9 